\title{
Tissue Inhibitor of Metalloproteinase-2 Polymorphisms and Risk for HIV-Associated Neurocognitive Disorder
}

\author{
HariOm Singh $\mathbb{D}^{1},{ }^{1}$ Sushma Jadhav, ${ }^{1}$ Dharmesh Samani, ${ }^{1}$ and Sumitra Nain ${ }^{2}$ \\ ${ }^{1}$ Department of Molecular Biology, National AIDS Research Institute, Pune 411026, India \\ ${ }^{2}$ Department of Pharmacy, University of Banasthali, Banasthali Vidyapith, Jaipur 302001, India \\ Correspondence should be addressed to HariOm Singh; hariomsgpgims@gmail.com
}

Received 13 March 2019; Accepted 15 May 2019; Published 28 May 2019

Academic Editor: Calogero Caruso

Copyright (C) 2019 HariOm Singh et al. This is an open access article distributed under the Creative Commons Attribution License, which permits unrestricted use, distribution, and reproduction in any medium, provided the original work is properly cited.

\begin{abstract}
The imbalance between MMPs and TIMPs is associated with the HIV dissemination tissue damage pathology neurodegenerative disorders, including HAND. Genetic variations in the TIMP gene may modulate the neurocognitive disorder in HIV patients. Hence, we evaluated the genetic variants of TIMP-2 (-418G/C, 303G/A) gene with the risk of HAND. Genotyping of TIMP-2 polymorphism was performed in 50 patients with HAND, 100 no HAND, and 154 healthy controls by PCR-RFLP. TIMP-2 $-418 \mathrm{GC}$ and 303AA genotypes represented a predominant risk for HAND severity $(\mathrm{OR}=1.55, P=0.30 ; \mathrm{OR}=4.58, P=0.24)$. The variant $-418 \mathrm{CC}$ genotype, $-418 \mathrm{~A}$ allele, had exhibited a significant risk for the acquisition of $\mathrm{HAND}(\mathrm{OR}=12.55, P=0.026$; $\mathrm{OR}=2.66, P=0.004)$. TIMP-2 303GA, 303AA genotype, and 303A allele evinced a higher risk for HAND severity $(\mathrm{OR}=1.82, P$ $=0.14 ; \mathrm{OR}=1.70, P=0.63$; and $\mathrm{OR}=1.68, P=0.12$ ). In HIV patients, TIMP-2 -418CC genotype and $-418 \mathrm{C}$ allele significantly occurred in comparison to healthy controls $(\mathrm{OR}=10.10, P=0.006 ; \mathrm{OR}=2.02, P=0.009)$. In the intermediate and early HIV disease stage, TIMP-2 -418CC genotype was significantly increased compared with healthy controls $(11.1 \%$ vs. $1.3 \%$, $\mathrm{OR}=14.63, P=0.01 ; 16.9 \%$ vs. $1.3 \%, \mathrm{OR}=14.51, P=0.002)$. In patients with HAND among tobacco and alcohol users, TIMP-2 -418CC genotype displayed a risk for HAND severity $(\mathrm{OR}=3.96, P=0.26$; $\mathrm{OR}=4.83, P=0.19)$. On multivariate logistic regression, TIMP-2 303AA genotype, advanced stage, and gender had a risk for HAND severity $(\mathrm{OR}=28.98, P=$ $0.02 ; \mathrm{OR}=2.35, P=0.070$; and $\mathrm{OR}=2.36, P=0.04$ ). In conclusion, TIMP-2 $-418 \mathrm{G} / \mathrm{C}$ polymorphism independently, along with alcohol and tobacco, may have an impact on the acquisition of HAND and its severity. TIMP-2 303G/A polymorphism bare a risk for HAND severity.
\end{abstract}

\section{Introduction}

Human immunodeficiency virus (HIV) directly invades the brain in a short period following the infection. The central nervous system (CNS) effects by replicating in macrophages and microglia and enhancing the inflammatory and neurotoxic responses in the host [1]. HIV-associated neurocognitive disorder (HAND) is a complication that occurs in HIV-infected patients. HAND is a neurocognitive impairment that has an asymptomatic neurocognitive impairment (ANI), mild neurocognitive disorder (MND), and HIVassociated dementia (HAD) [2]. Studies from India have reported a very high prevalence of HAND $(32.50 \%$ and $35 \%$ ) [3]. According to a study, the incidence of development of HIV-associated dementia (HAD) was nearly about 20-
$30 \%$ in a precombined antiretroviral therapy (cART) era and reduced to $10 \%$ in the post-cART era. Thus, the occurrence of HAD was found notably reduced in the postcART era [4]. The occurrence of HAD is estimated to be nearly $6 \%$ in India $[5,6]$. HIV subtypes (clade), dosedependent drug reactions, coinfections, and extracellular matrix (ECM) proteases are important in the modulation of HAND pathogenesis [7-9]. Extracellular matrix, a notable proportion of the CNS, contributes to alterations of ECM in the brain and may lead to mild cognitive impairment (MCI) [10]. An imbalance ratio of the matrix metalloproteinases (MMPs)/tissue inhibitors of matrix metalloproteinases (TIMPs) is associated with degradation of the ECM. The pathogenesis of inflammation-related diseases is associated with the degradation of the ECM [11]. The disparity between 
MMPs and TIMPs is mainly concerned with neurodegenerative diseases including Alzheimer's disease, ischemia, HAD, and other coinfection in HIV such as hepatitis C [12-14]. Due to the neurotoxic properties, MMPs and endogenous tissue inhibitors of MMPs (TIMPs) are widely studied to elucidate the pathogenesis of HAND [15]. Irregular expression of MMPs and TIMPs disturbs the blood-brain barrier (BBB) and allows the neurotoxic substance to penetrate into nerve cells leading to cell death $[16,17]$. In HAND patients, the plasma level of MMP-2/TIMP-2 was significantly higher as compared to the patients without HAND [15]. Collectively, active ECM is degraded by MMPs, which is tightly regulated by its inhibitor TIMPs. TIMP is a family of antiproteinases, is composed of four members (TIMP-1, 2, 3, and 4), and inhibits the activity of MMPs. Specifically, the MMP-2 and TIMP-2 play a significant role in maintaining the integrity in healthy tissues and regulate cell growth and apoptosis [18].

A secretary protein, TIMP-2, is located at $17 \mathrm{q} 25$, which inhibits the proteolytic activity of matrix metalloproteinase 2 (MMP-2) [19]. The genetic variations of $M M P-2$ and TIMP-2 are linked to low transcriptional activity and with the risk of several diseases [20-23]. TIMP-2 (-418G/C, 303G/A) polymorphisms are located in the promoter region and known to have an influence on the transcriptional activity and occurrence of the tumor $[20,24,25]$. Genetic variation of TIMP-2 is also associated with the risk of the malignant tumor and cancer $[23,26]$. TIMP-2 (-418G/C, 303G/A) polymorphisms and haplotype CGC were associated with the risk of gastric cancer and abdominal aortic aneurysm (AAA) [27, 28]. The GT (TIMP-2 $\left.-418^{*} \mathrm{G} / 303^{*} \mathrm{~T}\right)$ haplotype was associated with an increased risk of prostate cancer $(\mathrm{OR}=1.78 ; 95 \% \mathrm{CI}$ : 1.18-2.69, $P=0.006, \quad P c=0.024)$ [29]. TIMP-2 -418GC genotype showed a protective effect against prostate cancer (32.6\% vs. $14.8 \%, P=0.037, \mathrm{OR}=0.346)$ [30]. Although no association of TIMP-2 gene polymorphisms with the increased risk of prostate cancer, cervical cancer, myocardial infarction (MI) or coronary artery disease (CAD), and relapsing-remitting multiple sclerosis (RRMS) was reported [29, 31-33]. However, genetic variation of TIMP-2 (-418G/C, 303G/A) gene in patients with and without HAND is still unknown. Hence, the present study is projected to evaluate the genetic variants of TIMP-2 $(-418 \mathrm{G} / \mathrm{C}$ and $303 \mathrm{G} / \mathrm{A})$ gene with the risk of HAND from Western India.

\section{Materials and Methods}

2.1. Subjects. The number of patients with HAND was 50, which were enrolled from December 2013 to November 2015 with the confirmation of International HIV-associated Dementia Score (IHDS) $<9.5$ and documented evidence for HIV positive. The number of patients without HAND was 100, which were also recruited and were showing IHDS score $>9.5$ indicating without HAND status from the outdoor patient clinics of the National AIDS Research Institute, Pune. Patients having concurrent untreated opportunistic infections and febrile illness currently or in the past 15 days were excluded from HAND and without HAND groups. Simultaneously, one hundred fifty-four age and ethnicity-matched healthy controls with the negative status of hepatitis $B$ and $\mathrm{C}$, tuberculosis, and HIV serum negative from SD Bioline ELISA test were recruited from the same clinics. The questionnaire, personal interviews, and review of case records were used to collect the patient's clinical data. The guidelines of IHDS 2005 (grant 2008) were used for dementia scaling by the clinician. Estimation of the CD4 cell count was done by FACS. CD 4 counts $<200$ cells $/ \mathrm{mm}^{3}, 200-350$ cells $/ \mathrm{mm}^{3}$, and $>350$ cells $/ \mathrm{mm}^{3}$ were considered as advanced, intermediate, and early stage of HIV infection, respectively. The predesigned questionnaire was used to record the tobacco and alcohol usage. The institutional ethics committee (NARI/EC-2011/06 dated 13th October 2011) approved the study, a written and signed informed consent (ICF version 1.0 dated 18 April 2011) was taken from all participants.

2.2. DNA Extraction. Two $\mathrm{ml}$ peripheral blood sample was collected and stored at $-700^{\circ} \mathrm{C}$ prior to DNA extraction. Genomic DNA extraction was done from the peripheral blood leukocyte pellet using the Blood Genomic DNA Miniprep Kit of AxyPrep (Axygen Biosciences) according to the protocol given by the manufacturer.

2.3. Genotyping. Polymerase chain reaction-restriction fragment length polymorphism (PCR-RFLP) was used to genotype the TIMP-2 (-418G/C and 303G/A) polymorphisms. Primers for the amplification of TIMP-2 -418G/C and $303 \mathrm{G} / \mathrm{A}$ were taken as described $[28,34]$. PCR was performed in a total volume of $25 \mu \mathrm{l}$ with $10 \mathrm{pmol}$ of each primer, genomic DNA (100-150 ng), 2.5 mM deoxynucleotide triphosphates, PCR buffer containing $100 \mathrm{mM}$ Tris- $\mathrm{HCl}, \mathrm{pH} 8.6$, $50 \mathrm{mM} \mathrm{KCl}, 1.5 \mathrm{mM} \mathrm{MgCl}$, and 1.5 units of Taq polymerase (Bangalore Genies, India). The reaction conditions for TIMP-2 -418G/C were initial denaturation at $94^{\circ} \mathrm{C}$ for 3 min, followed by 35 cycles of denaturation at $94^{\circ} \mathrm{C}$ for 30 sec, annealing at $62^{\circ} \mathrm{C}$ for $1 \mathrm{~min}$, extension at $72^{\circ} \mathrm{C}$ for 1 $\mathrm{min}$, and a final extension at $72^{\circ} \mathrm{C}$ for $7 \mathrm{~min}$. The reaction conditions for TIMP-2 303G/A were initial denaturation at $94^{\circ} \mathrm{C}$ for $3 \mathrm{~min}$, followed by 35 cycles of denaturation at $94^{\circ} \mathrm{C}$ for $30 \mathrm{sec}$, annealing at $64^{\circ} \mathrm{C}$ for $1 \mathrm{~min}$, extension at $72^{\circ} \mathrm{C}$ for $1 \mathrm{~min}$, and a final extension at $72^{\circ} \mathrm{C}$ for $7 \mathrm{~min}$. All reactions were carried out in Thermal Cycler Model 2720 (Applied Biosystems, USA). PCR products and molecular weight markers were visualized in $2 \%$ agarose gel for confirmation of amplification. The expected amplicon size for TIMP-2-418G/C and 303G/A gene is $304 \mathrm{bp}$ and $119 \mathrm{bp}$, respectively. The PCR product of TIMP-2 -418G/C and 303G/A was digested using restriction enzyme AvaI and TspRI (MBI Fermentas Inc.). TIMP-2 -418G/C genotyping was done in $15 \%$ polyacrylamide gel using molecular weight markers and visualized after staining with ethidium bromide. TIMP-2 -418G/C genotyping was done based on the sequences and location of SNP, as assigned as follows: 230 bp, $51 \mathrm{bp}$, and $23 \mathrm{bp}$ for -418GG; $253 \mathrm{bp}, 230 \mathrm{bp}, 51 \mathrm{bp}$, and $23 \mathrm{bp}$ for $-418 \mathrm{GC}$; and 253 and $51 \mathrm{bp}$ for -418CC genotype and $103 \mathrm{bp}$ and $16 \mathrm{bp}$ for $303 \mathrm{GG} ; 119 \mathrm{bp}, 103 \mathrm{bp}$, and 16 bp for 303GA; and $119 \mathrm{bp}$ for 303AA. Other laboratory 
personnel did the regenotyping in $20 \%$ of samples from both patients and controls to rule out the technical discrepancy in genotyping. The genotyping error was assessed in $10 \%$ of samples by sequencing.

2.4. Statistical Analysis. The mean age variable was expressed as mean \pm standard deviation (SD). The deviation from the Hardy-Weinberg equilibrium in controls was calculated by $\chi^{2}$ goodness-of -fit test. We used the $\chi^{2}$ statistic (Fisher's exact test for cell size $<5$ ) to compare the genotype frequency between HIV patients with HAND vs. without HAND, HIV patients vs. healthy controls. Unconditional binary logistic regression analysis was used to derive the odds ratio (OR) and 95\% confidence interval (CI). SPSS software version 17.0 was used for statistical analysis, the two-sided value was used for the tests of statistical significance, and $P$ value less than $\leq 0.05$ was considered for significance. SNPStats online analysis tool was used to compare haplotype frequency among the respective groups [35]. Linkage disequilibrium (LD) was estimated between both the loci by calculating the relative $\mathrm{LD}$ value $\left(D^{\prime}\right)$ as $D^{\prime}=\mathrm{Dij} / D \max$ [36]. The Dij values were compared between patients with HAND and without HAND, HIV patients, and healthy controls.

\section{Results}

In the present study, we have included 50 patients with HAND, 100 patients without HAND, and 154 healthy individuals. The mean age (years \pm SD) of HIV patients with HAND, HIV patients without HAND, and healthy individuals was $40.34 \pm 3.41,39.45 \pm 7.34$, and $38.23 \pm 5.7$, respectively. The characteristics of HIV patients with HAND, HIV patients without HAND, and healthy individuals are shown in Table 1.

3.1. TIMP-2 (-418G/C and 303G/A) Polymorphisms and Patients with HAND. Frequency distribution of TIMP-2 (-418G/C and 303G/A) polymorphism in patients with HAND and no HAND is shown in Table 2. The predominance of TIMP-2 -418GC, 303GA, and 303AA genotypes and $303 \mathrm{~A}$ allele was found to be higher in HAND patients compared with no HAND (30.0\% vs. $20.0 \%$, OR $=1.55$, 95\% CI: $0.68-3.51, P=0.30 ; 34.0 \%$ vs. $28.0 \%, \mathrm{OR}=1.36$, 95\% CI: $0.64-2.89, P=0.42 ; 4.0 \%$ vs. $1.0 \%, O R=4.58,95 \%$ CI: $0.37-56.83, P=0.24$; and $21.0 \%$ vs. $15.0 \%, O R=1.57$, 95\% CI: $0.83-2.30, P=0.17$, respectively). Frequency of TIMP-2 -418CC genotype and -418C allele was distributed nearly alike between patients with HAND and without HAND (8.0\% vs.13.0\%, OR $=0.69,95 \%$ CI: $0.20-2.32, P$ $=0.55 ; 23.0 \%$ vs. $23.0 \%, \mathrm{OR}=0.99,95 \% \mathrm{CI}: 0.55-1.78, P$ $=0.99$, respectively). In patients with HAND, the prevalence of TIMP-2 -418GC and -418CC genotypes and -418C allele was observed to be higher when compared with healthy controls $(30.0 \%$ vs. $22.1 \%$, OR $=2.19,95 \%$ CI: $0.93-5.15, P=0.072 ; 8.0 \%$ vs. $1.3 \%, O R=12.55,95 \%$ CI: $1.36-115.90, P=0.026$; and $23.0 \%$ vs. $12.3 \%$, OR = 2.66, 95\% CI: $1.36-5.23, P=0.004$, respectively). The incidence of TIMP-2 303GA and 303AA genotypes and 303A allele was seemed to be higher in patients with HAND as compared to healthy controls $(34.0 \%$ vs. $29.2 \%$, OR $=1.82$, 95\% CI: $0.82-4.053, P=0.14 ; 4.0 \%$ vs. $1.9 \%, \mathrm{OR}=1.70$, 95\% CI: $0.20-14.64, P=0.63$; and $21.0 \%$ vs. $16.6 \%, \mathrm{OR}=$ 1.68, 95\% CI: $0.88-3.23, P=0.12$, respectively)

\subsection{TIMP-2 (-418G/C and 303G/A) Polymorphism and HIV} Patients. The frequency distribution of TIMP-2 (-418G/C and $303 \mathrm{G} / \mathrm{A}$ ) genotype/allele in HIV patients and healthy individuals is presented in Table 3. TIMP-2 -418CC genotype and $-418 \mathrm{C}$ allele were significantly overrepresented in HIV patients as compared to healthy controls $(13.0 \%$ vs. $1.3 \%$, $\mathrm{OR}=10.10,95 \% \mathrm{CI}: 1.97-51.68, P=0.006 ; 23.0 \%$ vs. $12.3 \%$, $\mathrm{OR}=2.02,95 \%$ CI: $1.20-3.41, \quad P=0.009$, respectively). Occurrence of TIMP-2 303GA and 303GG genotype and 303A allele was not different between HIV patients and healthy controls $(28.0 \%$ vs. $29.2 \%$, OR $=1.01,95 \%$ CI: $0.54-$ $1.89, P=0.97 ; 1.0 \%$ vs. $1.9 \%, \mathrm{OR}=0.34,95 \% \mathrm{CI}: 0.025-$ 4.66, $P=0.42$; and $15.0 \%$ vs. $16.6 \%, \mathrm{OR}=0.84,95 \% \mathrm{CI}$ : $0.49-1.46, P=0.54$, respectively).

3.3. Gene-Gene Interaction. The distribution of haplotype frequency of TIMP-2 (-418G/C and 303G/A) polymorphisms in respective groups is shown in Table 4 . While comparing patients with HAND vs. without HAND, HAND patients vs. healthy controls, and HIV patients vs. healthy individuals, the linkage disequilibrium (LD) $D^{\prime}$ between both the genes $\left(D^{\prime}=0.068,0.049\right.$, and 0.014$)$ was analyzed by the SNPStats online analysis tool. No significant differences were found in the comparison of LD values (Dij) between TIMP-2 polymorphisms $(P=0.32,0.84$, and 0.75$)$. It was anticipated that there could be an additive effect of these variations with the acquisition of HAND and its severity. In gene-gene interaction analysis, haplotype GG (TIMP$2-418^{*} \mathrm{G}$ and $303^{*} \mathrm{G}$ ) was considered as a reference. Occurrence of haplotypes GA and $\mathrm{CA}\left(-418^{*} \mathrm{G} / 303^{*} \mathrm{~A}\right.$, $\left.-418^{*} \mathrm{C} / 303^{*} \mathrm{~A}\right)$ was higher in HAND patients while comparing with no HAND (0.15 vs.0.10, OR $=1.70,95 \% \mathrm{CI}$ : 0.77-3.74, $P=0.19$; 0.05 vs. $0.04, \mathrm{OR}=1.34,95 \% \mathrm{CI}: 0.32$ 5.63, $P=0.69$, respectively). In patients with HAND, haplotype CG $\left(-418^{*} \mathrm{C} / 303^{*} \mathrm{G}\right)$ occurred significantly higher in comparison with healthy controls $(0.17$ vs. $0.10, \mathrm{OR}=2.55$, 95\% CI: 1.05-6.18, $P=0.04)$. On comparing between HAND patients and healthy controls, haplotypes GA and CA $\left(-418^{*} \mathrm{G} / 303^{*} \mathrm{~A},-418^{*} \mathrm{C} / 303^{*} \mathrm{~A}\right)$ occurred more frequent in HAND cases $(0.16$ vs. $0.15, \mathrm{OR}=1.57,95 \% \mathrm{CI}: 0.69-3.59$, $P=0.28 ; 0.05$ vs.0.01, $\mathrm{OR}=4.75,95 \% \mathrm{CI}: 0.58-38.60, P=$ 0.15 , respectively). In HIV patients, haplotypes CG and CA $\left(-418^{*} \mathrm{C} / 303^{*} \mathrm{~A},-418^{*} \mathrm{C} / 303^{*} \mathrm{~A}\right)$ were distributed predominantly higher in comparison to healthy controls ( 0.18 vs. $0.10, \mathrm{OR}=1.70,95 \% \mathrm{CI}$ : $0.94-3.08, P=0.08$; 0.04 vs. 0.01 , OR $=1.99,95 \%$ CI: $0.45-8.77, P=0.37$, respectively).

3.4. TIMP-2 (-418G/C and 303G/A) Polymorphism and HIV Disease Stages. The incidence of TIMP-2 -418 CC genotype was found to be significantly higher in early and intermediate HIV disease stages compared with healthy controls (16.9\% vs. $1.3 \%, \mathrm{OR}=14.51,95 \% \mathrm{CI}: 2.66-79.09, P=0.002$; $11.1 \%$ vs. $1.3 \%, \mathrm{OR}=14.63,95 \% \mathrm{CI}: 1.91-112.25, P=0.01$, 
TABLE 1: Characteristics of HIV patients with HAND, without HAND, and healthy controls.

\begin{tabular}{|c|c|c|c|}
\hline Subjects & $\begin{array}{l}\text { HIV patients HAND on ART } \\
\text { (years } \pm \text { SD) }\end{array}$ & $\begin{array}{l}\text { HIV patients on ART } \\
\text { (years } \pm \text { SD) }\end{array}$ & $\begin{array}{l}\text { Healthy controls } \\
\quad(\text { years } \pm \text { SD) }\end{array}$ \\
\hline Number of participants & 50 & 100 & 154 \\
\hline $\begin{array}{l}\text { Mean age and standard } \\
\text { deviation }\end{array}$ & $39.20+6.55$ & $38.28+7.62$ & $30.32+8.27$ \\
\hline Males & 23 & 65 & 113 \\
\hline Females & 27 & 35 & 41 \\
\hline Ethnicity & Western India & Western India & Western India \\
\hline \multicolumn{4}{|l|}{ Alcohol habit } \\
\hline Users & 11 & 29 & 0 \\
\hline Nonusers & 39 & 56 & 0 \\
\hline \multicolumn{4}{|l|}{ Tobacco habits } \\
\hline Users & 13 & 19 & 0 \\
\hline Non-users & 37 & 66 & 0 \\
\hline \multicolumn{4}{|l|}{ CD4 status } \\
\hline Advance stage (0-201) & 29 & 14 & NA \\
\hline Intermediate stage (201-350) & 20 & 27 & NA \\
\hline Early stage (351 above) & 1 & 59 & NA \\
\hline
\end{tabular}

HAND = HIV-associated neurological disorders; $\mathrm{ART}=$ antiretroviral therapy; $\mathrm{SD}=$ standard deviation; NA = not applicable.

respectively). The prevalence of TIMP-2 303GA genotype was almost alike between individuals with early HIV disease stage and healthy controls (33.9\% vs. $29.2 \%$, OR $=1.39,95 \%$ CI: 0.69-2.83, $P=0.36$ ) (Table 5).

3.5. Interaction between Gene and Environment. In geneenvironment analysis, we evaluated the risk for HAND in the presence of TIMP-2 polymorphisms and alcohol and tobacco usage. In tobacco using patients with HAND, the prevalence of TIMP-2 -418CC genotype was much frequent than nonusers $(15.4 \%$ vs. $5.4 \%, \mathrm{OR}=3.96,95 \% \mathrm{CI}: 0.37$ 42.62, $P=0.26$ ) (Table 6). Similarly, the distribution of TIMP-2 -418CC, 303GA, and 303AA genotypes was much more often in alcohol-consuming patients with HAND compared to no HAND ( $18.2 \%$ vs. $5.1 \%$, OR $=4.83$, 95\% CI: 0.47 $50.04, P=0.19 ; 36.4 \%$ vs. $33.3 \%$, $\mathrm{OR}=1.91,95 \% \mathrm{CI}: 0.38$ 9.57, $P=0.43$; and $9.1 \%$ vs. $2.6 \%, \mathrm{OR}=6.58,95 \% \mathrm{CI}: 0.31-$ 137.56, $P=0.23$, respectively). In alcohol-consuming HIV patients, TIMP-2 -418CC and 303GA genotypes occurred much than nonusers $(24.1 \%$ vs. $10.7 \%, \mathrm{OR}=2.03,95 \% \mathrm{CI}$ : $0.52-7.95, P=0.31 ; 31.0 \%$ vs. $25.0 \%, \mathrm{OR}=1.72,95 \% \mathrm{CI}$ : $0.55-5.34, P=0.35$ ) (Table 7).

3.6. Risk Factors of HAND: Multivariate Logistic Regression Analysis. We have looked the relationship of TIMP-2 $-418 \mathrm{G} / \mathrm{C}$ and $303 \mathrm{G} / \mathrm{A}$ polymorphisms, age, sex, tobacco, alcohol, and HIV disease stages with HAND was done by multivariate logistic regression analysis. TIMP-2 303AA genotype, advanced disease stage (CD4 <200), intermediate disease stage (CD4 201-350), and sex appeared as independent risk factor for HAND severity $(\mathrm{OR}=28.98$, $P=0.02 ; \mathrm{OR}=2.35, P=0.07 ; P \leq 0.001, \mathrm{OR}=6.65$; and $P$ $=0.04, \mathrm{OR}=2.36$, respectively). Tobacco users, TIMP-2 303GA genotype, have shown a risk for HAND severity (OR $=3.65, \quad P=0.42 ; \quad \mathrm{OR}=1.83, \quad P=0.16$, respectively).
TIMP-2 -418G/C polymorphism, age, and alcohol consumption have not shown a risk for HAND (Table 8).

\section{Discussion}

The degradation of ECM by MMPs is tightly regulated by tissue inhibitors of MMPs. The imbalance between MMPs and TIMPs affects the stability of BBB and also alters the activation of monocytes [15]. A higher ration of MMP-2/TIMP-2 plasma concentrations was reported in HAND patients [15]. Genetic variations in TIMP-2 gene may interrupt the balance, associated with the diseases susceptibility [37]. TIMP-2 -418G/C and 303G/A polymorphisms alter the expression profile and spatial conformation [24]. In the present study, the genotype distribution of TIMP-2 -418G/C gene in healthy individuals was almost similar with studies carried out by Zhang et al. and Srivastava et al. [28, 29] but differed from studies described by Mikolajczyk-Stecyna et al., Yaykasli et al., Aksoy et al., Alp et al., and Srivastava et al. [27, 3033]. Similarly, the genotype distribution of TIMP-2 303G/A gene in healthy controls was comparable with the study described by Srivastava et al. [29] and incomparable with a study done by Zhang et al. [28].

In this study, while comparing between patients with and without HAND vs. healthy controls, we found that TIMP-2 $-418 \mathrm{CC}$ genotype and $-418 \mathrm{C}$ allele were associated with the acquisition of $\mathrm{HAND}$ and its severity $(\mathrm{OR}=10.10, P=$ $0.006 ; \mathrm{OR}=2.66, P=0.004$; and $\mathrm{OR}=12.55, P=0.03)$. It is hypothesized that TIMP-2 $-418 \mathrm{G} / \mathrm{C}$ polymorphism may have a role in the acquisition of both HAND and its severity. On comparing between patients with and without HAND, we have observed that TIMP-2 303AA genotype has shown a risk for HAND severity $(\mathrm{OR}=4.58, P=0.24)$. The prevalence of the TIMP-2 -418CC genotype and C allele was associated with abdominal aortic aneurysm (AAA) patients [27]. 
TABLE 2: Frequency distribution of TIMP-2 (-418G/C and 303G/A) polymorphism in patients with vs. without HAND and patients with HAND vs. healthy controls.

\begin{tabular}{|c|c|c|c|c|}
\hline Genotypes TIMP-2 -418G/C & Patients with HAND $(N=50)(\%)$ & Patients without HAND $(N=100)(\%)$ & $P$ value & OR $(95 \% \mathrm{CI})$ \\
\hline GG & $31(62.0 \%)$ & $67(67.0 \%)$ & 1 & Reference \\
\hline GC & $15(30.0 \%)$ & $20(20.0 \%)$ & 0.30 & $1.55(0.68-3.51)$ \\
\hline $\mathrm{CC}$ & $4(8.0 \%)$ & $13(13.0 \%)$ & 0.55 & $0.69(0.20-2.32)$ \\
\hline Alleles TIMP-2 -418G/C & Patients with HAND $(N=100)(\%)$ & Patients without HAND $(N=200)(\%)$ & $P$ value & OR $(95 \% \mathrm{CI})$ \\
\hline G & $77(77.0 \%)$ & $154(77.0 \%)$ & 1 & Reference \\
\hline $\mathrm{C}$ & $23(23.0 \%)$ & $46(23.0 \%)$ & 0.99 & $0.99(0.55-1.78)$ \\
\hline Genotypes TIMP-2 303G/A & Patients with HAND $(N=50)(\%)$ & Patients without HAND $(N=100)(\%)$ & $P$ value & OR $(95 \% \mathrm{CI})$ \\
\hline GG & $31(62.0 \%)$ & $71(71.0 \%)$ & 1 & Reference \\
\hline GA & $17(34.0 \%)$ & $28(28.0 \%)$ & 0.42 & $1.36(0.64-2.89)$ \\
\hline AA & $2(4.0 \%)$ & $1(1.0 \%)$ & 0.24 & $4.58(0.37-56.83)$ \\
\hline Alleles TIMP-2 303G/A & Patients with HAND $(N=100)(\%)$ & Patients without HAND $(N=200)(\%)$ & $P$ value & OR $(95 \% \mathrm{CI})$ \\
\hline G & $79(79.0 \%)$ & $170(85.0 \%)$ & 1 & Reference \\
\hline A & $21(21.0 \%)$ & $30(15.0 \%)$ & 0.17 & $1.57(0.83-2.30)$ \\
\hline Genotypes TIMP-2 -418G/C & Patients with HAND $(N=50)(\%)$ & Healthy controls $(N=154)(\%)$ & $P$ value & OR $(95 \% \mathrm{CI})$ \\
\hline GG & $31(62.0 \%)$ & $118(76.6 \%)$ & 1 & Reference \\
\hline GC & $15(30.0 \%)$ & $34(22.1 \%)$ & 0.07 & $2.19(0.93-5.15)$ \\
\hline $\mathrm{CC}$ & $4(8.0 \%)$ & $2(1.3 \%)$ & 0.03 & $12.55(1.36-115.90)$ \\
\hline Alleles TIMP-2-418G/C & Patients with HAND $(N=100)(\%)$ & Healthy controls $(N=308)(\%)$ & $P$ value & OR $(95 \% \mathrm{CI})$ \\
\hline G & $77(77.0 \%)$ & $270(87.7 \%)$ & 1 & Reference \\
\hline $\mathrm{C}$ & $23(23.0 \%)$ & $38(12.3 \%)$ & 0.004 & $2.66(1.36-5.23)$ \\
\hline Genotypes TIMP-2 303G/A & Patients with HAND $(N=50)(\%)$ & Healthy controls $(N=154)(\%)$ & $P$ value & OR $(95 \% \mathrm{CI})^{\mathrm{a}}$ \\
\hline GG & $31(62.0 \%)$ & $106(68.8 \%)$ & 1 & Reference \\
\hline GA & $17(34.0 \%)$ & $45(29.2 \%)$ & 0.14 & $1.82(0.82-4.053)$ \\
\hline AA & $2(4.0 \%)$ & $3(1.9 \%)$ & 0.63 & $1.70(0.20-14.64)$ \\
\hline Alleles TIMP-2 303G/A & Patients with HAND $(N=100)(\%)$ & Healthy controls $(N=308)(\%)$ & $P$ value & OR $(95 \% \mathrm{CI})$ \\
\hline G & $79(79.0 \%)$ & $257(83.4 \%)$ & 1 & Reference \\
\hline A & $21(21.0 \%)$ & $51(16.6 \%)$ & 0.12 & $1.68(0.88-3.23)$ \\
\hline
\end{tabular}

$N=$ total number of subjects, $(\%)=$ frequency of genotypes/alleles, age-adjusted OR (odds ratio) and 95\% CI (confidence intervals) were derived from logistic regression models comparing the homozygous wild-type genotype/allele (GG genotype and G allele for TIMP-2 -418G/C and 303G/A were taken as reference) with other genotypes/alleles. Significant $P$ values $(P<0.05)$ and related OR $(95 \% \mathrm{CI})$ have been shown in bold.

TIMP-2 303G/A and -418G/C polymorphisms were associated with gastric cancer patient [28]. TIMP-2 -418GC genotype was associated with the reduced risk of prostate cancer $(P=0.037$, OR $=0.346)[30]$.

Genetic variants of TIMP-2 -418G/C gene were not associated with patients of relapsing-remitting multiple sclerosis (RRMS) [31]. TIMP-2 -418G/C and 303C/T polymorphisms were associated neither with the risk of developing prostate cancer nor with the risk of cervical cancer $[29,33]$.

In the present study, we have also analyzed the haplotypes among the groups. While comparing HAND patients and healthy controls, we found that haplotype CG was associated with HAND patients $(\mathrm{OR}=2.55, P=0.04)$. Similarly, when we compared between HIV patients and healthy controls, we found haplotype CG was likely to be associated with the risk for the development of HAND $(\mathrm{OR}=1.70, P=0.08)$. This suggests that haplotype $\mathrm{CG}$ might have a role in the acquisition of HAND and its severity. The frequency of haplotype CGC (MMP-21306C/T, TIMP-2 -418G/C and 303G/A) was apparently higher in patients with gastric cancer than the control group $(P<0.05)$ [28]. Haplotype results demonstrated that TIMP-2 (-418G/303T) was associated with a 1.8-fold increased risk of prostate cancer [29].

Present study was designed as case-control in which current CD4 cell count was taken as a substitute for disease progression. Since we do not know the exact time for the acquisition of HIV, the outcomes may be irritating by the time interval of HIV infection. In subgroup analysis, TIMP2 -418CC genotype was associated with individuals of intermediate HIV disease stage compared to healthy controls $(\mathrm{OR}=14.63, P=0.01)$. Individuals having intermediate HIV disease stage with TIMP-2 -418CC genotype may facilitate the risk for the advancement of HIV disease $(\mathrm{OR}=14.63, P=0.01)$.

We have also attempted to analyze the geneenvironment interaction to determine the etiology of disease $[38,39]$. To look at the interaction between gene and environment, we have performed a case-only analysis. We had not done a case-control analysis because the cases have to 
TABLE 3: Frequency distribution of TIMP-2 (-418G/C and 303G/A) polymorphisms in HIV patients without HAND and healthy controls.

\begin{tabular}{lcccc}
\hline Genotypes TIMP-2 -418G/C & Patients without HAND $(N=100)(\%)$ & Healthy controls $(N=154)(\%)$ & $P$ value & OR $(95 \%$ CI $)$ \\
\hline GG & $67(67.0 \%)$ & $118(76.6 \%)$ & 1 & Reference \\
GC & $20(20.0 \%)$ & $34(22.1 \%)$ & 0.92 & $1.04(0.52-2.08)$ \\
CC & $13(13.0 \%)$ & $2(1.3 \%)$ & $\mathbf{0 . 0 0 6}$ & $\mathbf{1 0 . 1 0}(\mathbf{1 . 9 7 - 5 1 . 6 8 )}$ \\
Alleles TIMP-2 -418G/C & Patients without HAND $(N=200)(\%)$ & Healthy controls $(N=308)(\%)$ & $P$ value & OR $(95 \% \mathrm{CI})$ \\
G & $154(77.0 \%)$ & $270(87.7 \%)$ & 1 & Reference \\
C & $46(23.0 \%)$ & $38(12.3 \%)$ & $\mathbf{0 . 0 0 9}$ & $\mathbf{2 . 0 2}(\mathbf{1 . 2 0 - 3 . 4 1})$ \\
Genotypes TIMP-2 303G/A & Patients without HAND $(\mathrm{N}=100)(\%)$ & Healthy controls $(N=154)(\%)$ & $P$ value & OR (95\% CI) \\
GG & $71(71.0 \%)$ & $106(68.8 \%)$ & 1 & Reference \\
GA & $28(28.0 \%)$ & $45(29.2 \%)$ & 0.97 & $1.01(0.54-1.89)$ \\
AA & $1(1.0 \%)$ & $3(1.9 \%)$ & 0.42 & $0.34(0.025-4.66)$ \\
Alleles TIMP-2 303G/A & Patients without HAND $(N=200)$ & Healthy controls $(N=308)(\%)$ & $P$ value & OR $(95 \% \mathrm{CI})$ \\
G & $170(85.0 \%)$ & $257(83.4 \%)$ & 1 & Reference \\
A & $30(15.0 \%)$ & $51(16.6 \%)$ & 0.54 & $0.84(0.49-1.46)$ \\
\hline
\end{tabular}

$\mathrm{N}=$ total number of subjects, $(\%)=$ frequency of genotypes/alleles; age-adjusted OR (odds ratios) and 95\% CI (confidence intervals) were derived from logistic regression models comparing the homozygous wild-type genotype/allele (GG genotype and $\mathrm{G}$ allele for TIMP-2 -418G/C and 303G/A were taken as reference) with other genotypes/alleles. Significant $P$ values $(P<0.05)$ and related OR $(95 \% \mathrm{CI})$ have been shown in bold.

TABLE 4: Frequency distribution of haplotypes of TIMP-2 (-418G/C and 303G/A) polymorphisms among patients with HAND, without HAND, and healthy controls.

\begin{tabular}{|c|c|c|c|c|}
\hline $\begin{array}{l}\text { Haplotypes TIMP-2 } \\
(-418 \mathrm{G} / \mathrm{C} \text { and } 303 \mathrm{G} / \mathrm{A})\end{array}$ & $\begin{array}{l}\text { Patients with HAND } \\
\qquad(N=100)\end{array}$ & $\begin{array}{l}\text { Patients without HAND } \\
\qquad(N=200)\end{array}$ & $P$ value & OR $(95 \% \mathrm{CI})$ \\
\hline GG & 0.61 & 0.66 & 1 & Reference \\
\hline CG & 0.17 & 0.18 & 0.94 & $1.03(0.52-2.02)$ \\
\hline GA & 0.15 & 0.10 & 0.19 & $1.70(0.77-3.74)$ \\
\hline CA & 0.05 & 0.04 & 0.69 & $1.34(0.32-5.63)$ \\
\hline Haplotypes TIMP-2 (-418G/C and 303G/A) & Patients with HAND $(N=100)$ & Healthy controls $(N=308)$ & $P$ value & OR ( $95 \% \mathrm{CI})$ \\
\hline GG & 0.61 & 0.72 & 1 & Reference \\
\hline CG & 0.17 & 0.10 & 0.04 & $2.55(1.05-6.18)$ \\
\hline GA & 0.16 & 0.15 & 0.28 & $1.57(0.69-3.59)$ \\
\hline CA & 0.05 & 0.01 & 0.15 & $4.75(0.58-38.60)$ \\
\hline Haplotypes TIMP-2 (-418G/C and 303G/A) & HIV patients $(N=200)$ & Healthy controls $(N=308)$ & $P$ value & OR ( $95 \% \mathrm{CI})$ \\
\hline GG & 0.66 & 0.72 & 1 & Reference \\
\hline CG & 0.18 & 0.10 & 0.08 & $1.70(0.94-3.08)$ \\
\hline GA & 0.10 & 0.15 & 0.61 & $0.84(0.43-1.64)$ \\
\hline CA & 0.04 & 0.01 & 0.37 & $1.99(0.45-8.77)$ \\
\hline
\end{tabular}

$N=$ total number of alleles, $(\%)=$ frequency of haplotypes; age-adjusted odds ratios and $95 \%$ CIs were derived from logistic regression models comparing the haplotype GG with other haplotypes. Significant $P$ values $(P<0.05)$ and related OR $(95 \% \mathrm{CI})$ have been shown in bold.

match with the controls in the population, then it may lead untrue interactions [40]. In an individual with HIV infection, consuming alcohol had a harmful effect on the CD4 cell count [41]. In our study, in patients with HAND using tobacco and alcohol, TIMP-2 -418CC genotype has shown a risk for HAND severity $(\mathrm{OR}=3.96, P=0.26$ and $\mathrm{OR}=$ $4.83, P=0.19)$. In alcohol-consuming patients with HAND, TIMP-2 303GA and 303AA genotypes revealed a risk for HAND severity $(\mathrm{OR}=1.91, P=0.43$ and $\mathrm{OR}=6.58, P=$ 0.23). In HIV patients consuming alcohol, TIMP-2
-418CC and 303GA genotypes have presented the risk for the acquisition of HAND $(\mathrm{OR}=2.03, P=0.31$ and $\mathrm{OR}=1.72, P=0.35) . M M P-2$ and TIMP-2 polymorphisms in the presence of tobacco usage were not associated with the risk of prostate cancer [29]. There was no significant association between TIMP-2 -418G/C gene polymorphism and cervical cancer risk due to tobacco usage $(\mathrm{OR}=1.70$, $P=0.139$ ) [33]. In multivariate logistic regression, we compared between patients with and without HAND, we found that TIMP-2 303AA genotype, advanced disease 
TABLE 5: Frequency distribution of TIMP-2 (-418G/C and 303G/A) polymorphisms in HIV disease stages of HIV patients (CD4 <200, 201350 , and $>350$ ) and healthy controls.

\begin{tabular}{|c|c|c|c|c|c|c|c|}
\hline \multirow{2}{*}{$\begin{array}{l}\text { Genotypes TIMP-2 } \\
-418 \mathrm{G} / \mathrm{C}\end{array}$} & \multirow{2}{*}{$\begin{array}{l}\text { Healthy controls }(N=154) \\
(\%)\end{array}$} & \multicolumn{2}{|c|}{ Early HIV disease stage } & \multicolumn{2}{|c|}{$\begin{array}{l}\text { Intermediate HIV } \\
\text { disease stage }\end{array}$} & \multicolumn{2}{|c|}{$\begin{array}{c}\text { Advanced HIV disease } \\
\text { stage }\end{array}$} \\
\hline & & $\begin{array}{c}N=59 \\
(\%)\end{array}$ & OR $(P)$ & $\begin{array}{l}N=27 \\
(\%)\end{array}$ & OR $(P)$ & $\begin{array}{c}N=14 \\
(\%)\end{array}$ & OR $(P)$ \\
\hline GG & $118(76.6 \%)$ & $35(59.3 \%)$ & Reference & $20(74.1 \%)$ & Reference & $12(85.7 \%)$ & Reference \\
\hline GC & $34(22.1 \%)$ & $14(23.7 \%)$ & $1.35(0.46)$ & $4(14.8 \%)$ & $0.70(0.57)$ & $2(14.3 \%)$ & $\begin{array}{c}0.65 \\
(0.60)\end{array}$ \\
\hline $\mathrm{CC}$ & $2(1.3 \%)$ & $10(16.9 \%)$ & $\begin{array}{c}14.51 \\
(0.002)\end{array}$ & $3(11.1 \%)$ & $\begin{array}{l}14.63 \\
(0.01)\end{array}$ & $0(0.0 \%)$ & NS \\
\hline \multirow{2}{*}{ Genotypes TIMP-2 303G/A } & \multirow{2}{*}{$\begin{array}{l}\text { Healthy controls }(N=154) \\
(\%)\end{array}$} & \multicolumn{2}{|c|}{ Early HIV disease stage } & \multicolumn{2}{|c|}{$\begin{array}{l}\text { Intermediate HIV } \\
\text { disease stage }\end{array}$} & \multicolumn{2}{|c|}{$\begin{array}{c}\text { Advanced HIV disease } \\
\text { stage }\end{array}$} \\
\hline & & $\begin{array}{l}N=59 \\
(\%)\end{array}$ & OR $(P)$ & $\begin{array}{l}N=27 \\
(\%)\end{array}$ & OR $(P)$ & $\begin{array}{c}N=14 \\
(\%)\end{array}$ & OR $(P)$ \\
\hline GG & $106(68.8 \%)$ & $38(68.8 \%)$ & Reference & $21(77.8 \%)$ & Reference & $12(85.7 \%)$ & Reference \\
\hline GA & $45(29.2 \%)$ & $20(33.9 \%)$ & $1.39(0.36)$ & $6(22.2 \%)$ & $0.86(0.77)$ & $2(14.3 \%)$ & $\begin{array}{c}0.50 \\
(0.39)\end{array}$ \\
\hline AA & $3(1.9 \%)$ & $1(1.7 \%)$ & $0.67(0.76)$ & $0(0.0 \%)$ & NS & $0(0.0 \%)$ & NS \\
\hline
\end{tabular}

$N=$ number of subjects, $(\%)=$ frequency of subjects; odds ratios and $95 \%$ CIs were derived from logistic regression models comparing the homozygous wildtype genotype (GG genotype for TIMP-2 -418G/C and 303G/A was taken as reference) with other genotypes. Significant $P$ values $(P<0.05)$ and related OR have been shown in bold.

TABLE 6: Frequency distribution of TIMP-2 (-418G/C and 303G/A) genotypes in tobacco using HIV patients with and without HAND.

\begin{tabular}{|c|c|c|c|c|}
\hline \multicolumn{5}{|l|}{ HIV patients with HAND } \\
\hline Genotypes TIMP-2 -418G/C & $\begin{array}{c}\text { Tobacco users } \\
N=13(\%)\end{array}$ & $\begin{array}{c}\text { Nonusers } \\
N=37(\%)\end{array}$ & $P$ value & OR $(95 \%$ CI $)$ \\
\hline GG & $7(53.8 \%)$ & $24(64.9 \%)$ & 1 & (Reference) \\
\hline GC & $4(30.8 \%)$ & $11(29.7 \%)$ & 0.76 & $1.27(0.27-6.03)$ \\
\hline $\mathrm{CC}$ & $2(15.4 \%)$ & $2(5.4 \%)$ & 0.26 & $3.96(0.37-42.62)$ \\
\hline Genotypes TIMP-2 303G/A & $\begin{array}{c}\text { Tobacco users } \\
N=13(\%)\end{array}$ & $\begin{array}{c}\text { Nonusers } \\
N=37(\%)\end{array}$ & $P$ value & OR (95\% CI) \\
\hline GG & $9(69.2 \%)$ & $22(59.5 \%)$ & 1 & (Reference) \\
\hline GA & $4(30.8 \%)$ & $13(35.1 \%)$ & 0.79 & $0.81(0.18-3.65)$ \\
\hline $\mathrm{AA}$ & $0(0.0 \%)$ & $2(5.4 \%)$ & NS & - \\
\hline \multicolumn{5}{|l|}{ HIV patients without HAND } \\
\hline Genotypes TIMP-2- 418G/C & $\begin{array}{c}\text { Tobacco users } \\
N=19(\%)\end{array}$ & $\begin{array}{c}\text { Nonusers } \\
N=66(\%)\end{array}$ & $P$ value & OR $(95 \% \mathrm{CI})$ \\
\hline GG & $13(68.4 \%)$ & $43(65.2 \%)$ & 1 & (Reference) \\
\hline GC & $3(15.8 \%)$ & $13(19.7 \%)$ & 0.96 & $1.03(0.22-4.80)$ \\
\hline $\mathrm{CC}$ & $3(15.8 \%)$ & $10(15.2 \%)$ & 0.72 & $0.76(0.17-3.44)$ \\
\hline Genotypes TIMP-2 303G/A & $\begin{array}{c}\text { Tobacco users } \\
N=19(\%)\end{array}$ & $\begin{array}{c}\text { Nonusers } \\
N=66(\%)\end{array}$ & $P$ value & OR $(95 \% \mathrm{CI})$ \\
\hline GG & $15(78.9 \%)$ & $47(71.2 \%)$ & 1 & (Reference) \\
\hline GA & $4(21.1 \%)$ & $19(28.8 \%)$ & 0.56 & $0.68(0.19-2.50)$ \\
\hline $\mathrm{AA}$ & $0(0.0 \%)$ & $0(0.0 \%)$ & NS & NS \\
\hline
\end{tabular}

$N=$ number of subjects, $(\%)=$ frequency of subjects; odds ratios and 95\% CIs were derived from logistic regression models comparing the homozygous wildtype genotype (GG genotype for TIMP-2 -418G/C and 303G/A was taken as reference) with other genotypes. Tobacco status in 15 HIV-infected individuals was unknown, therefore excluded from the analysis.

stage (CD4 <200), intermediate disease stage (CD4 201-350), and sex were associated with severity of HAND $(\mathrm{OR}=28.98$, $P=0.02, \mathrm{OR}=2.35, P=0.07, \mathrm{OR}=6.65, P \leq 0.001, \mathrm{OR}=$
2.36, $P=0.04)$. It is hypothesized that HAND patients with TIMP-2 303G/A polymorphism, advanced, and intermediate stages are more susceptible to severity of HAND. 
TABLE 7: Frequency distribution of TIMP-2 (-418G/C and 303G/A) genotypes in alcohol using HIV patients with and without HAND.

\begin{tabular}{|c|c|c|c|c|}
\hline \multicolumn{5}{|l|}{ HIV patients with HAND } \\
\hline Genotypes TIMP-2 -418G/C & $\begin{array}{c}\text { Alcohol users } \\
N=11(\%)\end{array}$ & $\begin{array}{c}\text { Nonusers } \\
N=39(\%)\end{array}$ & $P$ value & OR $(95 \% \mathrm{CI})$ \\
\hline GG & $6(54.5 \%)$ & $25(69.1 \%)$ & 1 & (Reference) \\
\hline GC & $3(27.3 \%)$ & $12(30.8 \%)$ & 0.83 & $1.20(0.23-6.31)$ \\
\hline $\mathrm{CC}$ & $2(18.2 \%)$ & $2(5.1 \%)$ & 0.19 & $4.83(0.47-50.04)$ \\
\hline Genotypes TIMP-2 303G/A & $\begin{array}{c}\text { Alcohol users } \\
N=11(\%)\end{array}$ & $\begin{array}{c}\text { Nonusers } \\
N=39(\%)\end{array}$ & $P$ value & OR (95\% CI) \\
\hline GG & $6(54.5 \%)$ & $25(64.1 \%)$ & 1 & (Reference) \\
\hline GA & $4(36.4 \%)$ & $13(33.3 \%)$ & 0.43 & $1.91(0.38-9.57)$ \\
\hline AA & $1(9.1 \%)$ & $1(2.6 \%)$ & 0.23 & $6.58(0.31-137.56)$ \\
\hline \multicolumn{5}{|l|}{ HIV patients without HAND } \\
\hline Genotypes TIMP-2 -418G/C & $\begin{array}{c}\text { Alcohol users } \\
N=29(\%)\end{array}$ & $\begin{array}{c}\text { Nonusers } \\
N=56(\%)\end{array}$ & $P$ value & OR $(95 \% \mathrm{CI})$ \\
\hline GG & $20(69.0 \%)$ & $36(64.3 \%)$ & 1 & (Reference) \\
\hline GC & $2(6.9 \%)$ & $14(25.0 \%)$ & 0.16 & $0.30(0.057-1.61)$ \\
\hline $\mathrm{CC}$ & $7(24.1 \%)$ & $6(10.7 \%)$ & 0.31 & $2.03(0.52-7.95)$ \\
\hline Genotypes & $\begin{array}{c}\text { Alcohol users } \\
N=29(\%)\end{array}$ & $\begin{array}{l}\text { Non-users } \\
N=56(\%)\end{array}$ & $P$ value & OR (95\% CI) \\
\hline \multicolumn{5}{|l|}{ TIMP-2 303G/A } \\
\hline GG & $20(69.0 \%)$ & $42(75.0 \%)$ & 1 & (Reference) \\
\hline GA & $9(31.0 \%)$ & $14(25.0 \%)$ & 0.35 & $1.72(0.55-5.34)$ \\
\hline $\mathrm{AA}$ & $0(0.0 \%)$ & $0(0.0 \%)$ & NS & NS \\
\hline
\end{tabular}

$N=$ number of subjects, $(\%)$ = frequency of subjects; odds ratios and 95\% CIs were derived from logistic regression models comparing the homozygous wildtype genotype (GG genotype for TIMP-2 -418G/C and 303G/A was taken as reference) with other genotypes. Alcohol status in 15 HIV-infected individuals was unknown, therefore excluded from the analysis.

TABLE 8: Multivariate analysis between patients with and without HAND.

\begin{tabular}{|c|c|c|c|c|c|}
\hline Variables & B & S.E. & df & $P$ value & OR (95\% CI) \\
\hline$-418 \mathrm{GG}$ & & & 2 & 0.67 & \\
\hline$-418 \mathrm{GC}$ & 0.357 & 0.460 & 1 & 0.43 & $1.42(0.58-3.52)$ \\
\hline$-418 \mathrm{CC}$ & -0.189 & 0.66 & 1 & 0.77 & $0.82(0.22-3.05)$ \\
\hline 303GG & & & 2 & 0.04 & \\
\hline 303GA & 0.60 & 0.43 & 1 & 0.16 & $1.83(0.78-4.29)$ \\
\hline \multirow[t]{2}{*}{$303 \mathrm{AA}$} & 3.36 & 1.48 & 1 & 0.02 & $28.98(1.59-527-23)$ \\
\hline & & & 2 & 0.001 & \\
\hline Intermediate disease stage (CD4 201-350) & 1.895 & 0.525 & 1 & $<0.001$ & $6.65(2.37-18.63)$ \\
\hline Advanced disease stage (CD4 <200) & 0.857 & 0.473 & 1 & 0.07 & $2.35(2.35-5.95)$ \\
\hline Age & 0.048 & 0.030 & 1 & 0.10 & $1.05(0.99-1.11)$ \\
\hline Sex & 0.861 & 0.429 & 1 & 0.04 & $2.36(1.02-5.47)$ \\
\hline Tobacco user & 1.296 & 0.637 & 1 & 0.42 & $3.65(1.04-12.73)$ \\
\hline Alcohol user & -1.038 & .634 & 1 & 0.10 & $0.35(0.10-1.22)$ \\
\hline
\end{tabular}

TIMP-2 -418G/C and 303G/A polymorphism; age 18-50 years, sex, tobacco user, alcohol user, baseline CD4. Significant values $(<0.05)$ represented and related OR $(95 \% \mathrm{CI})$ have been shown in bold.

\section{Conclusion}

TIMP-2-418G/C polymorphism and its haplotype could be linked with the acquisition of HAND, its severity, and advancement of the disease. Also, this polymorphism can facilitate the risk of HAND severity in tobacco- and alcohol-consuming patients with HAND. TIMP-2 303G/A polymorphism has also shown a risk for the HAND severity. The role of MMPs and TIMPs is diverse in the pathogenesis of the neurological disorders, and genetic 
polymorphisms have been associated with HIV diseases. Hence, the present study should be validated. Further study on TIMP and MMP polymorphisms in patients with HAND should be carried out in other population with larger samples.

\section{Abbreviations \\ MMP: Matrix metalloproteinase \\ TIMP: Tissue inhibitor of matrix metalloproteinase \\ HIV: Human immunodeficiency virus \\ HAND: HIV-associated neurocognitive disorder \\ HAD: HIV-associated dementia \\ cART: Combined antiretroviral therapy \\ ECM: Extracellular matrix \\ CNS: Central nervous system \\ MI: Myocardial infarction \\ CAD: Coronary artery disease \\ RRMS: Relapsing-remitting multiple sclerosis \\ IHDS: International HIV-associated dementia score \\ ELISA: Enzyme-linked immunosorbent assay.}

\section{Data Availability}

The data used to support the findings of this study are included within the article.

\section{Ethical Approval}

The study was approved by the institutional ethics committee of the National AIDS Research Institute, Pune. The data for alcohol and tobacco was filled in designed questionnaire form. Ethical approval No.: NARI/EC- 2011/06 dated 13th October 2011.

\section{Consent}

A written informed consent was signed by all individual participants included in the study.

\section{Conflicts of Interest}

The authors declare that they have no conflict of interest.

\section{Authors' Contributions}

Data generation was done by Sushma Jadhav. Data analysis and manuscript review were done by Dharmesh Samani. Sumitra Nain reviewed the manuscript. HariOm Singh did overall supervision.

\section{Acknowledgments}

We gratefully acknowledge the clinic in-charge Dr. R.R Gangakhedkar, Dr. Manisha Ghate, and Dr. Seema Sahay for the arrangement of community staff for recruitment of healthy control; Mansa Angadi, Shradha Bapat, and Jyoti Pawar for filling the clinical research proforma; Tumnan Katendra, Jai, and Iyesha for counseling of subject participants; and sisters Ujawala Ghule and Sunita for the collection of blood sample. The study was supported by research grant from Indian Council of Medical Research (ICMR) India. The grant number is HIV/50/152/10/2012-ECD-II.

\section{References}

[1] V. S. R. Atluri, S. P. Kanthikeel, P. V. B. Reddy, A. Yndart, and M. P. N. Nair, "Human synaptic plasticity gene expression profile and dendritic spine density changes in HIV-infected human CNS cells: role in HIV-associated neurocognitive disorders (HAND)," PLoS ONE, vol. 8, no. 4, article e61399, 2013.

[2] D. Saylor, A. M. Dickens, N. Sacktor et al., "HIV-associated neurocognitive disorder - pathogenesis and prospects for treatment," Nature Reviews Neurology, vol. 12, no. 4, pp. 234-248, 2016.

[3] S. Saini and K. V. Barar, "Assessment of neurocognitive functions in HIV/AIDS patients on HAART using the international HIV dementia scale," International Journal of Nutrition, Pharmacology, Neurological Diseases, vol. 4, no. 4, p. 252, 2014.

[4] G. J. Dore, A. McDonald, Y. Li, J. M. Kaldor, B. J. Brew, and National HIV Surveillance Committee., "Marked improvement in survival following AIDS dementia complex in the era of highly active antiretroviral therapy," AIDS, vol. 17, no. 10, pp. 1539-1545, 2003.

[5] A. K. Deshpande and M. M. Patnaik, "Nonopportunistic neurologic manifestations of the human immunodeficiency virus: an Indian study," Journal of the International AIDS Society, vol. 7, no. 4, p. 2, 2005.

[6] P. Satishchandra, A. Nalini, M. Gourie-Devi et al., "Profile of neurologic disorders associated with HIV/AIDS from Bangalore, south India (1989-96)," The Indian Journal of Medical Research, vol. 111, pp. 14-23, 2000.

[7] S. L. Letendre, R. J. Ellis, B. M. Ances, and J. A. McCutchan, "Neurologic complications of HIV disease and their treatment," Topics in HIV Medicine, vol. 18, no. 2, pp. 45-55, 2010.

[8] J. C. McArthur, J. Steiner, N. Sacktor, and A. Nath, "HIV-associated neurocognitive disorders: 'mind the gap'," Annals of Neurology, vol. 67, no. 6, p. NA, 2010.

[9] V. Valcour, R. Paul, S. Chiao, L. A. Wendelken, and B. Miller, "Screening for cognitive impairment in human immunodeficiency virus," Clinical Infectious Diseases, vol. 53, no. 8, pp. 836-842, 2011.

[10] L. W. Lau, R. Cua, M. B. Keough, S. Haylock-Jacobs, and V. W. Yong, "Pathophysiology of the brain extracellular matrix: a new target for remyelination," Nature Reviews Neuroscience, vol. 14, no. 10, pp. 722-729, 2013.

[11] D. Bonneh-Barkay and C. A. Wiley, "Brain extracellular matrix in neurodegeneration," Brain Pathology, vol. 19, no. 4, pp. 573-585, 2009.

[12] L. Kaczmarek, J. Lapinska-Dzwonek, and S. Szymczak, "Matrix metalloproteinases in the adult brain physiology: a link between c-Fos, AP-1 and remodeling of neuronal connections?," The EMBO Journal, vol. 21, no. 24, pp. 6643-6648, 2002.

[13] M. Larrousse, M. Laguno, M. Segarra et al., "Noninvasive diagnosis of hepatic fibrosis in HIV/HCV-coinfected patients," Journal of Acquired Immune Deficiency Syndromes, vol. 46, no. 3, pp. 304-311, 2007.

[14] C. M. Mastroianni, G. M. Liuzzi, G. D'Ettorre et al., "Matrix metalloproteinase-9 and tissue inhibitors of matrix 
metalloproteinase- 1 in plasma of patients co-infected with HCV and HIV," HIV Clinical Trials, vol. 3, no. 4, pp. 310315, 2002.

[15] Y. Xing, N. Shepherd, J. Lan et al., "MMPs/TIMPs imbalances in the peripheral blood and cerebrospinal fluid are associated with the pathogenesis of HIV-1-associated neurocognitive disorders," Brain, Behavior, and Immunity, vol. 65, pp. 161-172, 2017.

[16] S. E. Lakhan, A. Kirchgessner, D. Tepper, and A. Leonard, "Matrix metalloproteinases and blood-brain barrier disruption in acute ischemic stroke," Frontiers in Neurology, vol. 4, 2013.

[17] N. L. Webster and S. M. Crowe, "Matrix metalloproteinases, their production by monocytes and macrophages and their potential role in HIV-related diseases," Journal of Leukocyte Biology, vol. 80, no. 5, pp. 1052-1066, 2006.

[18] T. Hayakawa, K. Yamashita, E. Ohuchi, and A. Shinagawa, "Cell growth-promoting activity of tissue inhibitor of metalloproteinases-2 (TIMP-2)," Journal of Cell Science, vol. 107, pp. 2373-2379, 1994.

[19] D. W. Seo, H. Li, L. Guedez et al., “TIMP-2 Mediated Inhibition of Angiogenesis," Cell, vol. 114, no. 2, pp. 171-180, 2003.

[20] Y. A. De Clerck, M. I. Darville, Y. Eeckhout, and G. G. Rousseau, "Characterization of the promoter of the gene encoding human tissue inhibitor of metalloproteinases-2 (TIMP-2)," Gene, vol. 139, no. 2, pp. 185-191, 1994.

[21] A. E. Hegab, T. Sakamoto, Y. Uchida et al., "Association analysis of tissue inhibitor of metalloproteinase 2 gene polymorphisms with COPD in Egyptians," Respiratory Medicine, vol. 99, no. 1, pp. 107-110, 2005.

[22] X. Miao, C. Yu, W. Tan et al., "A functional polymorphism in the matrix metalloproteinase-2 gene promoter $(-1306 \mathrm{C} / \mathrm{T})$ is associated with risk of development but not metastasis of gastric cardia adenocarcinoma," Cancer Research, vol. 63, no. 14, pp. 3987-3990, 2003.

[23] C. Yu, Y. Zhou, X. Miao, P. Xiong, W. Tan, and D. Lin, "Functional haplotypes in the promoter of matrix metalloproteinase-2 predict risk of the occurrence and metastasis of esophageal cancer," Cancer Research, vol. 64, no. 20, pp. 7622-7628, 2004

[24] H. Alakus, N. Afriani, U. Warnecke-Eberz et al., "Clinical impact of MMP and TIMP gene polymorphisms in gastric cancer," World Journal of Surgery, vol. 34, no. 12, pp. 28532859, 2010.

[25] S. J. Price, D. R. Greaves, and H. Watkins, "Identification of novel, functional genetic variants in the human matrix metalloproteinase-2 gene: role of Sp1 in allele-specific transcriptional regulation," The Journal of Biological Chemistry, vol. 276, no. 10, pp. 7549-7558, 2001.

[26] Y. Zhou, C. Yu, X. Miao et al., "Substantial reduction in risk of breast cancer associated with genetic polymorphisms in the promoters of the matrix metalloproteinase- 2 and tissue inhibitor of metalloproteinase-2 genes," Carcinogenesis, vol. 25, no. 3, pp. 399-404, 2004.

[27] J. Mikolajczyk-Stecyna, A. Korcz, M. Gabriel, K. Pawlaczyk, G. Oszkinis, and R. Slomski, "Gene polymorphism -418 G/C of tissue inhibitor of metalloproteinases 2 is associated with abdominal aortic aneurysm," Journal of Vascular Surgery, vol. 61, no. 5, pp. 1114-1119, 2015.

[28] D. Y. Zhang, J. Wang, G. Q. Zhang, X. Q. Chu, J. L. Zhang, and Y. Zhou, "Correlations of $M M P-2$ and TIMP-2 gene polymorphisms with the risk and prognosis of gastric cancer," Interna- tional Journal of Clinical and Experimental Medicine, vol. 8, no. 11, pp. 20391-20401, 2015.

[29] P. Srivastava, T. A. Lone, R. Kapoor, and R. D. Mittal, “Association of promoter polymorphisms in MMP2 and TIMP2 with prostate cancer susceptibility in North India," Archives of Medical Research, vol. 43, no. 2, pp. 117-124, 2012.

[30] K. O. YAYKAŞLI, M. A. KAYIKÇI, N. YAMAK et al., "Polymorphisms in MMP-2 and TIMP-2 in Turkish patients with prostate cancer," Turkish Journal of Medical Sciences, vol. 44, no. 5, pp. 839-843, 2014.

[31] D. Aksoy, O. Ates, S. Kurt, B. Cevik, and O. Sumbul, “Analysis of MMP2-1306C/T and TIMP2G-418C polymorphisms with relapsing remitting multiple sclerosis," Journal of Investigative Medicine, vol. 64, no. 6, pp. 1143-1147, 2016.

[32] E. Alp, A. Yilmaz, M. Tulmac et al., "Analysis of MMP-7 and TIMP-2 gene polymorphisms in coronary artery disease and myocardial infarction: a Turkish case-control study," The Kaohsiung Journal of Medical Sciences, vol. 33, no. 2, pp. 7885, 2017.

[33] P. Srivastava, S. Pandey, B. Mittal, and R. D. Mittal, "No association of matrix metalloproteinase $[\mathrm{MMP}]-2(-735 \mathrm{C}>\mathrm{T})$ and tissue inhibitor of metalloproteinase [TIMP]-2 $(-418 \mathrm{G}>\mathrm{C})$ gene polymorphisms with cervical cancer susceptibility," Indian Journal of Clinical Biochemistry, vol. 28, no. 1, pp. 13-18, 2013.

[34] D. Krex, H. Rohl, I. R. Konig, A. Ziegler, H. K. Schackert, and G. Schackert, "Tissue inhibitor of metalloproteinases-1, -2, and -3 polymorphisms in a white population with intracranial aneurysms," Stroke, vol. 34, no. 12, pp. 2817-2821, 2003.

[35] X. Sole, E. Guino, J. Valls, R. Iniesta, and V. Moreno, "SNPStats: a web tool for the analysis of association studies," Bioinformatics, vol. 22, no. 15, pp. 1928-1929, 2006.

[36] A. Cox, N. J. Camp, M. J. H. Nicklin, F. S. di Giovine, and G. W. Duff, "An analysis of linkage disequilibrium in the interleukin-1 gene cluster, using a novel grouping method for multiallelic markers," American Journal of Human Genetics, vol. 62, no. 5, pp. 1180-1188, 1998.

[37] S. Faisst and S. Meyer, "Compilation of vertebrate-encoded transcription factors," Nucleic Acids Research, vol. 20, no. 1, pp. 3-26, 1992.

[38] Y. Deng, B. Newman, M. P. Dunne, P. A. Silburn, and G. D. Mellick, "Case-only study of interactions between genetic polymorphisms of GSTM1, P1, T1 and Z1 and smoking in Parkinson's disease," Neuroscience Letters, vol. 366, no. 3, pp. 326-331, 2004.

[39] S. Greenland, "The effect of misclassification in the presence of covariates," American Journal of Epidemiology, vol. 112, no. 4, pp. 564-569, 1980.

[40] T. Y. Chen, Y. C. Li, Y. F. Liu et al., "Role of MMP14 gene polymorphisms in susceptibility and pathological development to hepatocellular carcinoma," Annals of Surgical Oncology, vol. 18, no. 8, pp. 2348-2356, 2011.

[41] J. H. Samet, S. J. Phillips, N. J. Horton, E. T. Traphagen, and K. A. Freedberg, "Detecting alcohol problems in HIVinfected patients: use of the CAGE questionnaire," AIDS Research and Human Retroviruses, vol. 20, no. 2, pp. 151155, 2004. 


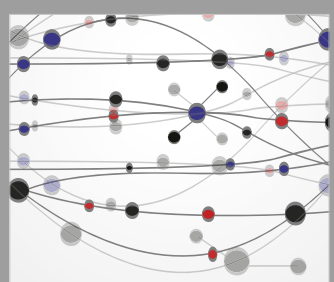

The Scientific World Journal
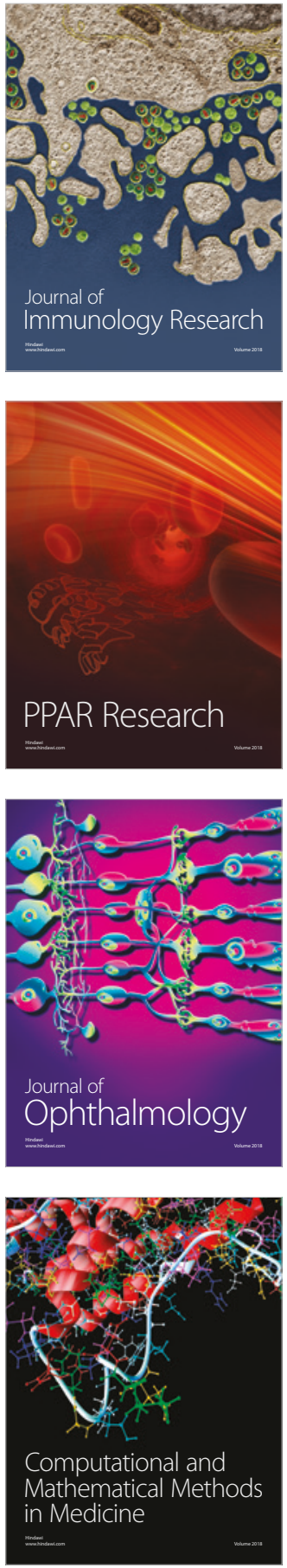

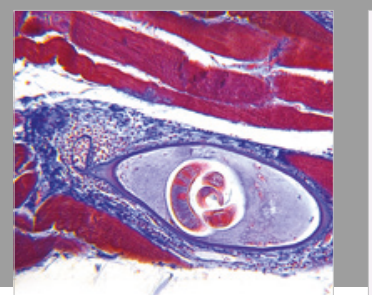

Gastroenterology Research and Practice

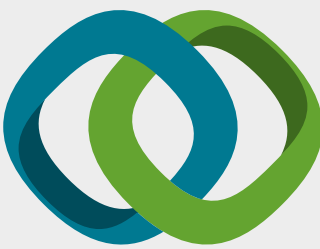

\section{Hindawi}

Submit your manuscripts at

www.hindawi.com
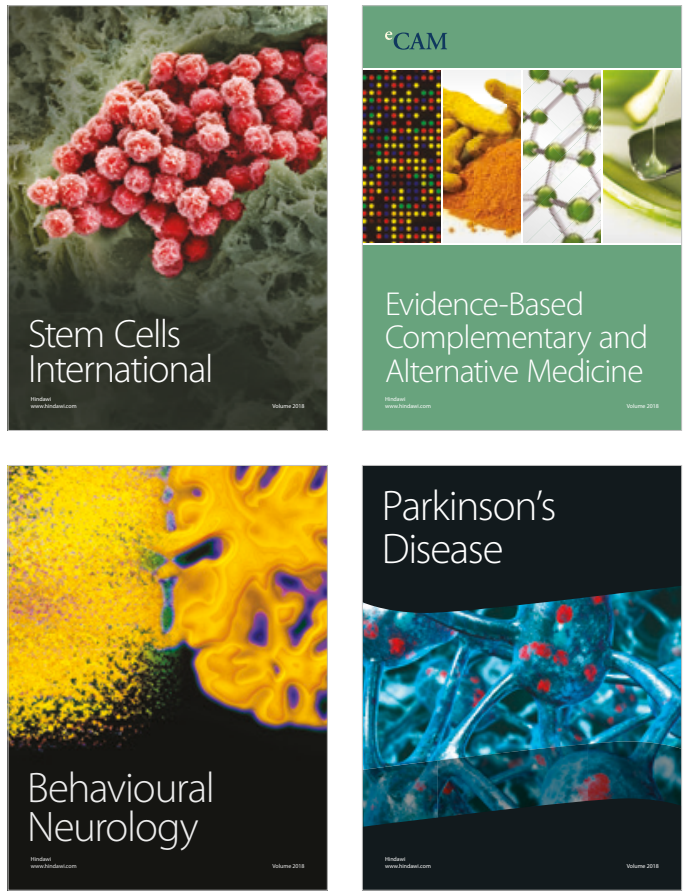

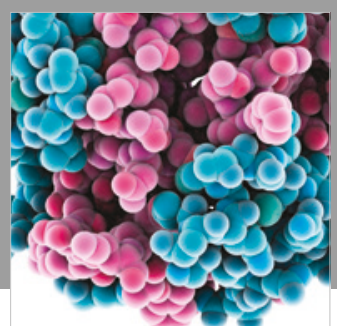

ournal of

Diabetes Research

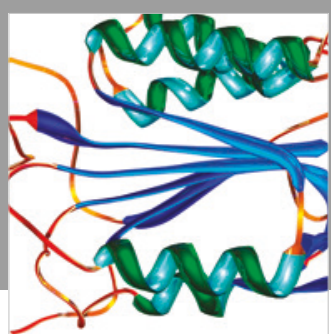

Disease Markers
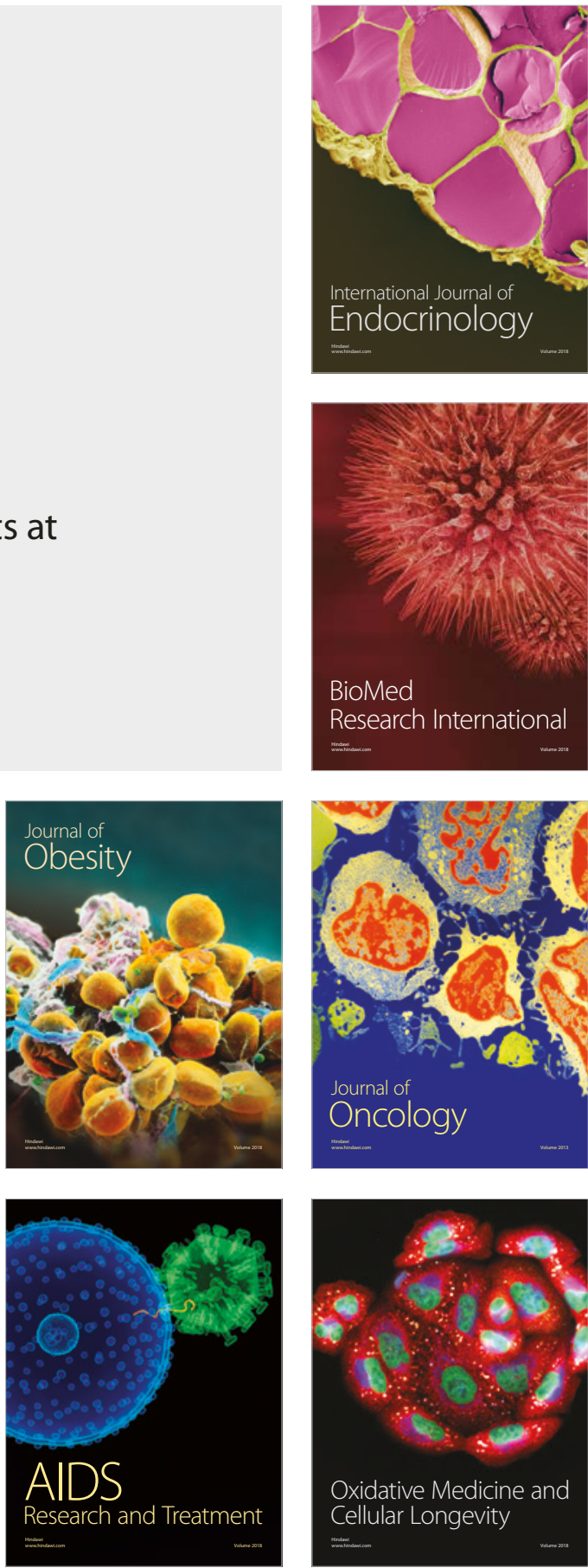